38 INVESTIGATION OF THE RELATIONSHIP BETWEEN THE USE OF CONTINUOUS POSITIVE AIRWAY PRESSURE (CPAP) THERAPY AND WEIGHT CHANGE IN OVERWEIGHT AND OBESE PATIENTS WITH SLEEP APNOEA

Pawel Urban. Liverpool Heart and Chest Hospital, UK

10.1136/bmjresp-2021-bssconf.33

Obstructive Sleep Apnoea Hypopnea Syndrome (OSAHS) is a disorder characterised by events of partial or complete cessation in breathing during sleep and an excessive daytime somnolence. The pathophysiology of the condition is multifactorial. Obesity is one of the major risk factors for OSAHS. The relationship between both is not yet fully understood, but it is well evidenced that losing weight can improve OSAHS symptoms. Continuous Positive Airway Pressure (CPAP) is a first line of treatment in moderate to severe OSAHS, however, its effect on weight loss remains unclear. The aim of this service evaluation was to investigate if there is any relationship between compliance with CPAP and weight change in order to assess the need for weight loss clinic. To achieve the aim, we performed a retrospective analysis of data sets of 77 overweight and obese OSAHS patients who were treated with CPAP for a minimum 5 years was performed. Correlation between CPAP compliance and weight loss was assessed with a Pearsons correlation. 38/77 participant's weight increased from baseline to visit 5, 36/77 experienced weight loss and 3 subjects remained weight neutral. 50/77 patient's data sets demonstrated compliance greater than 95\% across 5 years, a further 27 subjects had compliance less than 95\%. Assessment for a correlation between compliance and percentage change in body weight after 5 years of treatment demonstrated no correlation $r=0.045$ ( $\mathrm{p}$ 0.69). This report backs up similar findings that CPAP compliance alone does not promote weight change, a multidisciplinary approach to weight loss management may improve long term patient outcomes.

\section{ADHERENCE TO NON-INVASIVE VENTILATION IN OBESE CHILDREN WITH OBSTRUCTIVE SLEEP APNOEA OR OBESITY HYPOVENTILATION SYNDROME}

${ }^{1}$ Hannah Williams*, 'Sakina Dastagir, 'Jo Gregory, ${ }^{1}$ Ruth Wakeman, ${ }^{1,2}$ Federica Trucco, ${ }^{1}$ Alex Thomas, ${ }^{1}$ Rishi Pabary, ${ }^{1}$ Hui-Leng Tan, ${ }^{1}$ Ruth O'Reilly. ${ }^{1}$ Royal Brompton Hospital, London, UK; ${ }^{2}$ Dept Paediatric Neuroscience, Guy's and St Thomas NHS trust and Department Paediatric Respiratory medicine, London, UK

\subsection{6/bmjresp-2021-bssconf.34}

Introduction This study aimed to describe the cohort of obese children who were on respiratory support for obstructive sleep apnoea (OSA) or nocturnal hypoventilation in a tertiary respiratory centre and their adherence at 1 year.

Methods Clinical and cardiorespiratory polygraphy data were reviewed for children with a body mass index (BMI) $>25 \mathrm{~kg} /$ $\mathrm{m}^{2}$ established on NIV for OSA (AHI $\left.>1 \mathrm{ev} / \mathrm{Hr}\right)$ or OHS $\left(\mathrm{BMI}>30 \mathrm{~kg} / \mathrm{m}^{2} \text { and criteria for nocturnal hypoventilation }\right)^{1}$ from 2013-21. Children with neuro-disability were excluded. Nocturnal hypoventilation was defined as transcutaneous carbon dioxide $\left(\mathrm{TCO}_{2}\right)>6.7 \mathrm{kPa} \geq 25 \%$ total sleep time (TST). ${ }^{1}$ Studies less than 4 hours TST were excluded. Day time hypercapnia was defined as $\mathrm{TCO}_{2}>5.99 \mathrm{kPa} \geq 10$ minutes. ${ }^{1} \mathrm{NIV}$ compliance was $>4$ hours/night use for $>70 \%$ of nights. ${ }^{2}$
Abstract 39 Table 1 Baseline characteristics of children established on respiratory support $(n=13)$

\begin{tabular}{lc}
\multicolumn{2}{|c}{ Baseline characteristics of children established on respiratory support ( $\mathrm{n}=13$ ) } \\
\cline { 2 - 2 } Age at NIV initiation (years) & $\frac{\text { Median (range) }}{10.8(5.1-15.6)}$ \\
\hline BMI $\left(\mathrm{kg} / \mathrm{m}^{2}\right)$ & $36.2(28.6-47.3)$ \\
\hline Apnoea hypopnoea index events/h & $6.2(0-56.5)$ \\
\hline OAHI events/h & $2.9(0-56.4)$ \\
\hline CAHI events/h & $0.7(0-5.1)$ \\
\hline Mean oxygen saturations & $97 \%(91-98 \%)$ \\
\hline Oxygen desaturation index (3\%) dips/h & $12.3(0-58.5)$ \\
\hline Transcutaneous carbon dioxide (> 6.7kPa 25\% TST) & $\mathrm{n}=5(25-87 \%)$ \\
\hline
\end{tabular}

Results Data was obtained from 16 children $(9$ males, 7 females) of whom 2 children had a BMI of $25-30 \mathrm{~kg} / \mathrm{m}^{2}$, and $14>30 \mathrm{Kg} / \mathrm{m}^{2}$. Baseline polygraphy data was available on 13/ 16 children, 8 children had OSA only, 3 had OSA and nocturnal hypoventilation and 2 had and isolated OHS. 5 children (3M, 2F, age $9.0 \quad(4.5-16)$ years) had nocturnal hypoventilation and also had the highest BMI of the cohort, BMI median $36.2(28.6-47.3) \mathrm{kg} / \mathrm{m}^{2}$. Daytime hypercapnia was present in $4 / 9$ children with measurements, but only 2 had nocturnal hypoventilation. No child had a $\mathrm{TCO}_{2}$ increase $>10 \mathrm{mmHg}$ from wake to sleep. Children were established on NIV continuous $(n=11)$ and bilevel $(n=5)$. Only $2 / 14$ children with adherence data were adherent to respiratory support at 1 year. (Table 1).

Discussion Assessment for complications of excess weight should include day and night-time TCO2 monitoring as OHS was evident from 5 years. Adherence to NIV is poor and intensive multi-disciplinary input may improve this.

\section{REFERENCES}

1. Masa Eur Respir Rev 2019.

2. Schwab Am J Respir Crit Care Med 2013.

\section{OBJECTIVELY MEASURED SLEEP POSITION IN EARLY AND LATE PREGNANCY}

Louise O'Brien*. University of Michigan, Ann Arbor, USA

\subsection{6/bmjresp-2021-bssconf.35}

Introduction Whilst it has long been recognised that posture has a profound impact on maternal haemodynamics, few studies have extrapolated these practices to maternal sleep. Recently, findings from several countries have shown that selfreport of maternal going-to-sleep in the supine position increases the odds 2-8-fold for 3rd trimester stillbirth. However, none of the prior research has been able to objectively assess sleep position and it is unclear how many pregnant women spend time supine. The goal of the present study was to objectively assess sleep position and respiratory disturbance in pregnant women and to determine how these variables change across pregnancy.

Methods Pregnant women were recruited from a large academic medical centre prior to 19 weeks' gestation and invited to undergo home sleep testing using the WatchPAT device. Home sleep testing was repeated in late pregnancy. The proportion of supine sleep time was calculated and OSA was defined as an apnoea-hypopnoea index (AHI) $\geq 5$ events/hour. 